\title{
Can an unconventional Socio-technical System approach open the way to new solutions and new understanding?
}

\section{Trond Haga}

\begin{abstract}
Socio-technical System Design (STSD) was developed as an alternative to the prevailing Taylorist organisational design principles focusing on specialisation and standardisation. STSD emphasised quality of work and has thus been described as a strategy for "simple organisation and complex jobs". This may sound like a partial strategy for developing holistic, meaningful jobs. However, it is as much about developing efficient organisations with interactions between people and technology that increase company competitiveness. STSD has taken different directions in different countries/geographic areas. All these directions emphasise holistic job design and employee participation. However, approaches to achieving holistic job design and to the role of employee participation vary. The ongoing digital revolution, often labelled Industry 4.0, is rapidly changing the conditions for work in general. Tasks that were previously manual are being automated, and communications and information are being made available to an extent not seen until now. In this landscape, it is necessary to consider whether we have suitable approaches for facing the challenges posed by these technological developments.

In this paper, which considers two strands in the tradition of STSD theory and a case study, I will examine the need to introduce a familiar but rarely discussed or used STSD approach to major technological and organisational changes.
\end{abstract}

Keywords: socio-technical systems design, STSD approaches, organisational concepts, technology, work organisation, proposal box system, participation 


\section{Introduction}

In his influential book The Paradigm that Changed the Work Place, Frans M. van Eijnatten attempted to capture the history of STSD (van Eijnatten 1993). He divided the history of STSD into three distinct periods: (1) sociotechnical pioneering work, (2) classical STSD and (3) modern STSD. Van Eijnatten further divided the last period into four variants: (a) participative design, (b) integral organisational renewal (IOR), (c) democratic dialogue (DD) and (d) STSD in North America. In this paper I aim to analyse how two of these variants, IOR and DD, facilitate employee participation.

The geographical origin of IOR is the Netherlands. In modern times STSD development within this tradition has been about developing the IOR model (van Eijnatten 1993). However,

"The main objective for IOR has been to develop a systematic approach to design which supports improvements in both the quality of work and what is called 'the quality of the organisation"” (de Sitter et al. 1997:498).

Classical STSD has been criticised for the lack of progress in developing concepts and instruments and for being too strongly dependent on experts. This dependence may explain the lack of diffusion of the STSD approach. IOR has been under the influence of the Scandinavian DD model, and this tradition's participatory approach has been adopted by IOR. However, IOR has retained a strong expert component (de Sitter et al. 1997).

The developers of the IOR approach aimed to develop a generally applicable theory that joins social and technical systems in an optimised "best match". Thus the joint system should be as good at shortening delivery times as at improving jobs. The new paradigm for socio-technical design is based on a specific set of concepts that address the architecture of systems structure, capacity to control, ability to distinguish production and control structures, and cohesion between different structural parameters (de Sitter et al. 1997). IOR thus offers a very detailed set of structural principles in terms of design content. For instance, reducing the probability of the occurrence of disturbing events and adding regulatory potential are regarded as essential measures for systemic survival (Vriens and Achterbergh 2011).

The geographical origins of DD are in Scandinavia (van Eijnatten 1993). This STSD variant intentionally does not emphasise the work system design content; it is rather the development process and participation that are accentuated (van Eijnatten 1993, Gustavsen 2008). The reasoning for this turn was, in part, a scepticism about general theories, which were not considered useful. To understand the specific workplace, the notion of "local theory" was introduced (Elden 1983). It was thus the initiation of workplace processes that came to be at the centre of the further development of DD. Particular attention was paid to important procedural tools such as search and dialogue conferences, and employee participation was closely linked to these tools. However, it was not only such processes that were linked to the STSD tradition; the facilitation of participatory improvement processes was also included in the overall framework for work life, as in the Norwegian Basic Agreement (Gustavsen 2008). Twoparty co-operation to initiate improvement processes in companies was included in the Agreement, and formal cooperative bodies were created to support this approach.

The two STSD approaches have thus used various methods in their efforts to create complex jobs and simple organisations. The question that will be discussed in this paper is whether these approaches are relevant to the challenges that arise from the ongoing digital revolution (Brynjolfsson and McAfee 2014)20 and the accompanying

20 At present, a new wave of technology, known in Europe as "Industry 4.0", is receiving attention. Industry 4.0 consists of a set of new
technologies, including artificial intelligence, robotics, automation, big data, network sensors, data exchange, cloud computing and the Internet of Things. These interconnected technologies are anticipated to lead to major changes in business models, production processes, skills, needs and forms of co-operation. 
organisational changes. However, the need to redesign STSD emerges not only as a result of technological advances but is just as much a result of the lack of development of STSD approaches (Pava 1983, Pava 1986, de Sitter et al. 1997).

\section{Coping with uncertainty}

Uncertainty is part of the operational reality of businesses and organisations. However, as a result of the ongoing digital revolution, companies are confronted with more uncertainty than under normal, almost stable production conditions. Uncertainty calls for action from businesses and organisations if they are to survive. Organisationally, most businesses will respond to an increase in external uncertainty and complexity with an increase in internal complexity. This usually means creating new positions internally to handle threatening external conditions. However, there is a second option for dealing with uncertainty: reducing internal complexity. This may be achieved by distributing tasks and responsibilities internally (de Sitter et al. 1997).

The theory of STSD was developed along the lines of the second option (Emery 1959, de Sitter et al. 1997). The various STSD approaches that have evolved from the 1960s onwards share the aim of developing "complex jobs and simple organizations". The differences emerge when we delve into how to achieve this target. The reason for developing different approaches was the lack of diffusion of STSD in general in the 1960s and 70s. To enable a broader and faster diffusion, work was initiated in various environments and networks to develop more suitable approaches. The development of IOR in the Netherlands and DD in Scandinavia should be viewed from this perspective.

\section{A cybernetic approach to organisational structures}

To ensure a broader and faster diffusion, the Dutch IOR initiators laid out a unified strategy. First, they assumed that it was necessary to convince management about the economic benefits of STSD. Second, they anticipated the need to develop a shared set of well-elaborated design concepts, principles, rules and design sequences validated in practice. Such a design theory thus went far beyond traditional STSD, and the mission to develop it was taken up by a network of professionals organised by the Netherlands Institute for the Improvement of the Quality of Work and Organization (NKWO) (de Sitter et al. 1997). Their point of departure indicated that they would take a systemic approach, and so it transpired.

Cybernetics is a transdisciplinary approach for exploring regulatory systems, their structures, constraints and possibilities. The term is often used in a rather loose way to imply control of any system using technology. Thus, cybernetics is the scientific study of how humans and machines control and communicate with each other. Consequently, cybernetics is relevant for mechanical, physical, biological, cognitive and social systems. For instance, a cybernetic approach may be used to study how organisations deal with complexity, understood as disturbances threatening systemic survival (Vriens and Achterbergh 2011). This may be thought of in two ways: reducing the probability of the occurrence of disturbing events ("attenuation") or adding regulatory potential ("amplification") (de Sitter et al. 1997). Thus, the cybernetic approach is closely linked to a dedicated set of concepts (Vriens and Achterbergh 2011, van Eijnatten 1993, de Sitter et al. 1997), and to three fundamental concepts in particular: essential variables, amplification and attenuation. In what follows, these concepts will be given a content accommodated to cybernetic theory.

Ashby has described the "amplify" and "attenuate" methods in terms of the behaviour of a machine and the flow values of certain variables (Ashby 1958). He pays special attention to what he characterises as essential variables. 
These variables are closely linked to the survival of the machine: if they are outside certain limits for too long, the machine will have a breakdown or simply disintegrate. In the course of its survival, the machine may encounter all kinds of disturbing influences that threaten its essential variables, and in order to counter them, it depends on "regulatory potential": the potential to deal with disturbances. Given a particular set of disturbances, the machine should have the requisite regulatory variety, i.e., enough regulatory actions to cope with these disturbances. If not, it should try to extend its regulatory variety and action. This is what Ashby characterises as amplification of regulatory potential. If the disturbance is not repeated, another option is to decrease the probability of similar occurrences. Reducing the probability of occurrences of a disturbance is what Ashby characterises as attenuation.

The explanation above is given in terms of a machine, whereas the topic of this paper is organisational. How, then, can the terms essential variables, amplification and attenuation become relevant for such a topic? Generally, the three concepts encompass vital particular variables (essential variables), the capacity to extend regulatory variety and action (amplification), and reduction of the probability of occurrence of disturbances (attenuation).

Essential variables in an organisation, as in the case of the machine above, are closely linked to its survival (Vriens and Achterbergh 2011). As long as the essential variables stay within certain parameters, the organisation will survive. De Sitter proposes three classes of variables that an organisation should keep under control to survive: quality of organisation, quality of work and quality of working relations (Vriens and Achterbergh 2011). These classes can be further divided into external functional requirements and internal functional requirements. Table 1 contains what de Sitter considers as being the essential variables and their norm values. The logic of his argument is that if the internal functional requirements are met, then the external functional requirements are met and the organisation's viability is ensured.

Table 1. de Sitter's essential variables and norm values (de Sitter et al., 1997).

\begin{tabular}{|c|c|c|}
\hline Variable & External functional requirements & Internal functional requirements \\
\hline $\begin{array}{l}\text { Quality of } \\
\text { organisation }\end{array}$ & Order flexibility & $\begin{array}{l}\text { Short production cycle time } \\
\text { Sufficient product variations } \\
\text { Variable mix of products }\end{array}$ \\
\hline & Control over order realisation & $\begin{array}{l}\text { Reliable production and production time } \\
\text { Effective control of quality }\end{array}$ \\
\hline & Potential for innovation & $\begin{array}{l}\text { Strategic product development } \\
\text { Short innovation time }\end{array}$ \\
\hline Quality of work & $\begin{array}{l}\text { Low level of absenteeism } \\
\text { Low level of personnel turnover }\end{array}$ & $\begin{array}{l}\text { Controllable stress conditions } \\
\text { Opportunity (1) to be involved, (2) to learn and (3) to develop }\end{array}$ \\
\hline $\begin{array}{l}\text { Quality of } \\
\text { working relations }\end{array}$ & Effective communication & $\begin{array}{l}\text { Shared responsibility } \\
\text { Participation in communication }\end{array}$ \\
\hline
\end{tabular}

According to de Sitter, disturbances in the organisation may occur in two ways, broadly speaking: those that are and those that are not related to the structure of the organisation. Those not related to the organisational structure can be a source of disturbance (waiting times, etc.). Structures may also increase the probability of disturbances spreading if there is no regulatory potential to deal with them. In summary, for de Sitter, structural attenuation can be understood as a structure being designed in a way that stops disturbances (or at least reduces them to a minimum), and structural amplification can be understood as a structure having the capability to deal with disturbances.

De Sitter moves on to define structural design parameters for the avoidance or reduction of disturbances as much as for ensuring regulatory operation, a so-called organisational renewal of a company (van Eijnatten 1993). De 
Sitter thus sets up a comprehensive theory that contains the overall picture that I have tried to summarise above, and in addition he outlines a number of details to make the theory complete. His comprehensive theory thus includes the following:

1. different levels (class, external and internal requirements)

2. a set of design parameters (seven different)

3. a developed system for evaluating the parameters.

IOR is an applied design strategy for successful implementation of organisational change. Such implementation cannot be imposed, as it calls for a solid basis in the organisation. De Sitter clearly states that it is crucial that the redesign is carried out by the organisation's members themselves in a participatory manner. At the same time, he emphasises that socio-technical design, however participatory it may be, relies on design expertise (de Sitter 1993). Thus, participation is not a sufficient condition for setting the organisation in motion or for changing its structures.

The main objection to IOR is that it is a rigid approach. The recipe that has been developed may be regarded as the only available solution to socio-technical challenges and thus limit the space of opportunities. Furthermore, the strong focus on efficiency and effectiveness may be regarded as an enhancer of the existing regime and, to a lesser extent, as a challenger to the same. At the same time, the approach will require specially trained personnel and thus may be capable of preventing a strong and broad distribution.

\section{A procedural approach to improvement}

The Scandinavian-funded DD approach strongly emphasises the initiation of workplace processes. The diffusion of STSD following its classical period was weak. Only in some countries and in some professional environments did the approach gain a foothold. The dependence on professionals, in particular, was regarded as a hindrance to a further spread of the approach; the headline issue of complex jobs and simple organisations was regarded as less of an obstacle than this dependence. For a large number of companies, this meant hiring in external professionals who lacked knowledge of the company, its culture, its way of operating and the composition of its internal expertise.

An obvious alternative was to strongly encourage workplace processes, in terms of both promotion and preparation. In Norway, in particular, initiation of workplace processes was regarded as essential. The approach highlighted by Greenwood and Levin emphasises the inherent potential in individual contributions from employees both for developing the workplace, the individuals and the working environment and for supporting the removal of obstacles (cybernetics) (Greenwood and Levin 2007).

However, individual contributions have not been encouraged blindly. In shaping alternatives to conventional hierarchical organisations, the concept of "industrial democracy" has been vital. This concept emerged from the early action research (AR) efforts in the US, the Tavistock developments and the Norwegian Democracy Project (Greenwood and Levin 2007). Fundamental arguments in favour of democracy in an organisational setting as the main tool for shaping a democratic society were forcefully developed by Carole Pateman (Pateman 1970). One obvious way to promote industrial democracy was to institutionalise it through work life agreements, and that became the case in Scandinavia.

Here, employees are encouraged by their social partners, i.e., by unions and management, through democratic dialogue to participate in developing the workplace and the work organisation (van Eijnatten 1993). This dialogue is regulated in Norway through the Company Development Contract as part of the Basic Agreement between employer and employee confederations (Gustavsen 2008, van Eijnatten 1993). The main concepts behind DD are 
learning (being open to new ideas) and dialogue (participation in open discussion). DD both confers on employees the privilege to form local theories and empowers them to come up with their own solutions. The main focus is on process rather than structure.

To fully understand the relationship between management and unions, one must look at how co-operation structures are set up within the companies (Table 2).

Table 2. Co-operation structures within companies.

\begin{tabular}{|c|c|}
\hline Body & Members \\
\hline Board & The owners and union representatives are members of the Board. \\
\hline Company committee & $\begin{array}{l}\text { The management and the unions are members of the committee. The chairmanship alternates } \\
\text { between management and union representatives. }\end{array}$ \\
\hline Department committee & The department manager and employees from the department are members of the committee. \\
\hline Yearly co-operation & $\begin{array}{l}\text { Each year a conference is arranged that focuses on co-operative conference business } \\
\text { development. } 21\end{array}$ \\
\hline Work environment & $\begin{array}{l}\text { Management and elected safety delegates. The chairmanship committee alternates between } \\
\text { management and union representatives. }\end{array}$ \\
\hline
\end{tabular}

From a development perspective, all these arenas are important. The company committee will discuss and make decisions on strategic improvement and training initiatives. The representatives on this committee are free to put forward matters for discussion and decision. In this way, the employees can adopt specific initiatives and promote them within the committee. The union representatives/employees are thus not present for information only, but rather to discuss strategic issues and participate in the decision-making process.

The most important body for supporting participation is likely to be the department committee, which discusses improvement proposals, small and large, that are promoted by personnel in different departments. If a proposed initiative is relatively inexpensive, the committee may make the implementation decision themselves. If the initiative is more expensive and/or needs to be processed or studied further, it may be referred to the development department. Either way, the department committee is a driver in improvement work within the company and handles a number of proposals, especially minor ones. These structures provide employees with a number of forums where they can influence strategic choices and promote proposals for improvement/change. Combined with a focus on dialogue, this enables employees to play an active part in the development of their own workplace.

However, to enhance further the diffusion of STSD, the emergence of links between local company-specific processes came to be regarded as vital (van Eijnatten 1993, Gustavsen 2008). Instead of unfolding within single organisations with networking across organisational boundaries, projects would now have network construction as their prime target (van Eijnatten 1993, Haga 2007). With local/regional networks as a point of departure, diffusion became identical to the expansion of local/regional actor configurations. Resources to front or support networking were scarce; consequently, the use of regional research resources became the solution. Another distinctive feature of STSD development in Norway is the closeness of its links with AR. STSD has almost been removed from the vocabulary and has been replaced with AR. Because STSD was closely identified with processes, participation and the use of research, the distance to AR was short.

Compared with IOR and de Sitter's cybernetic theory, the agenda for the model procedural-based improvement may appear vague. However, it is not vague because of a lack of strategy. Fundamentally, the approach focuses on the improvement agenda, the improvement process and the participatory dimension. As Table 2 shows, there is a

21 The set-up of co-operative bodies is company-specific and belongs to the company in each case. 
strong emphasis on participation: the theorist and practitioners operating within this variant of STSD believe in participation at the strategic level, as well as in the more practical improvement projects/implementation activities. However, compared to the structural IOR approach outlined above, the focus on organisational design and interaction between man and machine is less visible. One criticism that may be directed at both IOR and DD is that they lack the ability to capture what follows Industry 4.0. The availability of information makes it possible to envision entirely new organisational solutions in the place of traditional hierarchical ones (Brynjolfsson and McAfee 2014).

\section{Method}

The study this article is based on was set up with a team of researchers from the company's research partner and a team of internal resources from the company. On the one hand, prior to the project start-up, the research team had a close relation to the company, based on previous collaborative development projects. On the other hand, the team from the company consisted of personnel with considerable experience of development work, even in some cases a research background. A representative from the company acted as head of the project. However, it was a joint team that

- developed the funding application to the Norwegian Research Council (NRC)

- prepared an implementation plan for the project with a set of defined work areas

- distributed tasks and responsibilities between representatives from research and the company.

To be eligible for funding by the NRC, it was necessary for a group of companies to participate in the project. The company invited two other suppliers and an industrial network hub to join the project, and all three accepted and became partners in the project. To formally manage the project, a steering committee consisting of the CEOs in the companies was established. A representative of the research partner was also a member of the steering committee. The head of the project and the lead researcher met in the steering committee meetings.

The aim of the study was to develop a production system, i.e., a framework for improving the work organisation of the case company and the interaction with its partners. The use of technology and the interaction between technology and organisation was also addressed to support the development. At the same time, it was important to maintain and further develop the strong tradition of participation in the company. The project execution was planned in modules which individually took account of the various aspects that were to be addressed. Thus, one module covered the development of the production system, another one the development of the digital proposal box, and so on. Each module was set up in a way that ensured representative representation in the work groups, and the researchers were also included. The groups developed and tested new solutions for different user and management groups, in this way receiving the group's feedback for further work on the solutions. Start-up and progress varied for the different groups, so whereas some groups are about to finalise their documentation, other groups have not progressed quite so far.

The process may be presented as a stepwise one with the following steps: (1) define target or aim, (2) define detailed content, (3) design the process, system or product/solution, (4) develop the pilot and developments including testing and (5) deliver complete solutions (see Figure 1). As indicated, finalisation of each step had to be cleared by the project committee that overlooked the progress of the different teams. The feedback loops that were designed in served several purposes. First, they allowed for a reality check on the teams' suggestions by letting them receive feedback from others in the organisation. Second, they allowed for internal reflection within each team. 


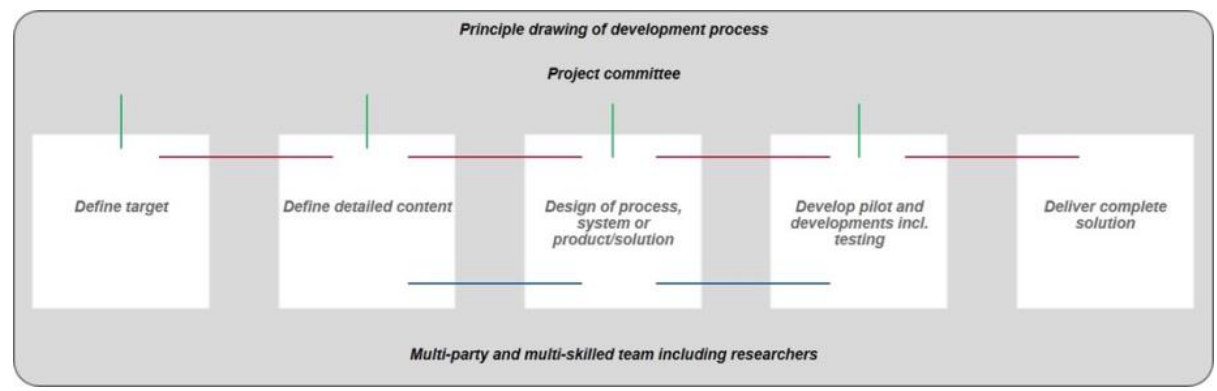

Figure 1. Principles of the development process.

Thus, the method used was not set up on the basis of cybernetic assumptions but rather on a procedural assumption. In spite of this, the aim of establishing the production system was to determine a framework for further development of the organisation, the technology and the interaction between them.

The members of each team had different responsibilities and tasks. When activities were planned, implemented and evaluated, this was done jointly as a team, but it was the individual responsible who carried out the activities and summarised what had been done. The tasks or phenomena were thus not studied from the outside; the research was largely performed in the field. Most of the activities performed were planned and carried out with personnel from the company. Participation was thus a fundamental ingredient in the set-up of the project. To ensure a balanced representation, the unions were actively used as a resource, as well as for legitimation and mobilisation.

\section{The case: preparing for a new reality}

New international production concepts and new technologies22 are being introduced at a fast pace. Businesses are challenged to take up new concepts and technologies, since these have the potential to improve their performance and increase their competitiveness. The concepts introduced are largely international and take little account of national contexts.23 Various new technologies, such as artificial intelligence, robots and digitalisation, will provide great opportunities if they are set up efficiently. However, it should be observed that new concepts and technologies often take little account of the relationships between process, organisation, technology and competence.

The socio-technical system approach focuses on the fact that technology is not deterministic: it allows for choice (Emery 1993, Eijnatten 1993). This means focusing on the choices that technology provides in order to establish effective processes and work organisation. At the same time, this approach aims to weaken organisational disturbances, thereby reinforcing the factors that ensure stable, efficient operation (Vriens and Achterbergh 2011). The focus is thus on how the socio-technical system is set up locally within the established framework. How the organisation is set up matters and should be based on the concept of "joint optimisation" (Emery 1959). The approach emphasises the work content as being holistic and not Tayloristic in its design (Eijnatten 1993). The sociotechnical system is not static but in constant development. The development takes place both as a consequence of external influences and as an effect of internally improvement work within the business.

The case company is characterised by one-of-a-kind dynamic production for the construction of offshore/onshore installations. The value chain is complex, as much of the product is supplied by subcontractors. At the same time,

\footnotetext{
22 Production concepts include Total Quality Management, Business Process Reengineering, Lean and Production systems, and broad technologies include automation, robotics, digitalization and the more general Industry 4.0.

23 For example, national laws and general agreements.
} 
design engineering and construction work in parallel to reduce completion time. A further consequence of this parallel processing is the high number of changes, which, combined with the high number of companies involved in the value chain, illustrates the need for close interaction and control to ensure an optimal installation sequence and distribution of installation personnel. This is necessary to meet the stringent quality requirements in the offshore industry. The fact that the products are one-of-a-kind and that the production process is complex limits the possibility of standardising the project implementation. Thus, the project implementation is also one-of-a-kind, which negatively affects productivity (Galbraith 1974).

The case presented below may function as an illustration of how companies can take new steps to prepare for the new reality. In this case, the company has launched several comprehensive development initiatives in parallel to proactively face up to the industry 4.0 reality. It has launched a large digitalisation programme that includes initiatives in a number of directions. The main components cover the areas of automated project set-up, automated engineering, digital lifecycle information, digital yard and digital project management. Each of these areas is in turn composed of a number of digitalising projects.

In parallel to this programme, the company has initiated an industrial research project to explore the appropriateness of using the production system for engineering-to-order (ETO) companies.24 Production systems have been developed by many companies and have become standard in many industries. As each of these systems is designed for an individual business, the term "company-specific production system" (XPS, where X stands for the name of the company) has emerged. The most famous example, and model for later production systems, is the Toyota Production System, TPS.

A production system aims to increase the efficiency and productivity of the company in question. As strategies and competitive priorities, capabilities, culture and history vary between companies, it is rational for a production system to be adapted to the business and therefore be unique to the company. The same tools will not provide good productivity in each case. The strength of an XPS is that it allows the company to choose from the variety of effective production and enhancement philosophies, and to focus on those that are most suitable.

An important aspect in the thinking behind a production system is that it should be a lasting programme, not merely an improvement project. Consequently, it requires lasting leadership support at all levels, and it allows for longterm planning to develop the production system and to carry out improvement work generally. In particular, longterm thinking and perseverance have proved to be essential. A study of the implementation of the Volvo Production System, VPS, in Volvo Trucks factories worldwide makes this clear (Netland 2013).

A production system is intended to increase productivity, distinctive business and a lasting programme. The system consists of principles and guidelines as to how the company can achieve good levels of efficiency. These principles are grouped into different categories, often highlighting certain parent elements (or building blocks) that together make up an easily recognisable figure. To help operationalise each principle, companies can choose to highlight a set of tools, either for use in daily operations or in the improvement work. These tools are often a mixture of methods that the company has developed internally and methods that have been tested and found reliable in the literature and in textbooks. While the elements and principles are mainly permanent, the tools will to a great extent be developed over time (and some may be discarded in the process).

Creating good profitability in complex projects is demanding. The aim of the Simplex project is to make this type of production process smoother and more precise. We will solve this challenge by developing a production system that integrates the actors in the value chain in a better way than is done today. The key principles of the system are

24 The Simplex Project was financed by the Norwegian Research Council for a period of four years, starting in 2016 and focusing on developing a production system for an ETO company. 
simplicity and intuition: the necessary information is to be made available in ways that are perceived by the system's actors and users as logical and easy to understand and that are communicated in a smooth manner.

As part of the research programme, a model for such a production system was developed (Figure 2).

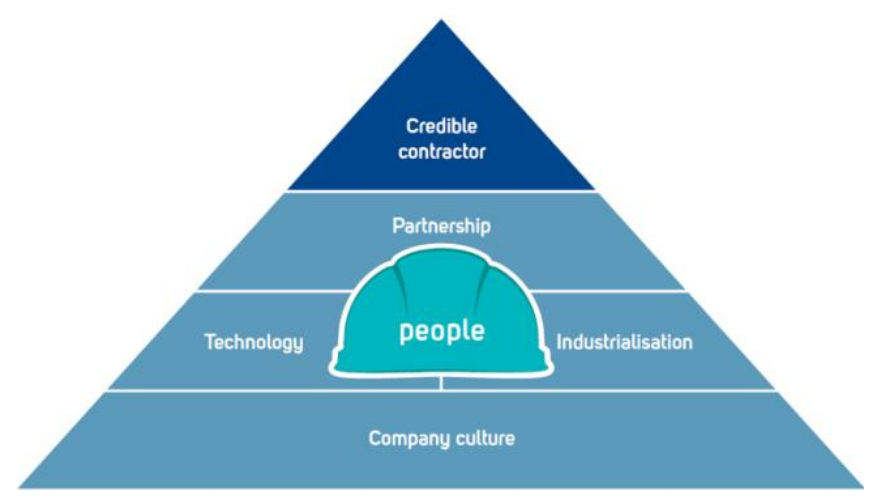

Figure 2. XPS developed for the case company.

The system was developed in two steps over a period of approximately a year. Fundamental input was obtained through a series of team gatherings. The team was put together to cover different parts of the organisation and the production process, and union representatives were present at the team gatherings. In this way, we hoped to create the information base necessary to design a first version of the production system. On the basis of the information available, the researchers and project management in the company drafted a model and an accompanying description of the system. This first version was then presented at a number of gatherings, where feedback indicated that a second version was necessary. This second version was designed using previously collected information, feedback on the first version and reflection within the project team. When the model was complete, it was presented to local management and received their endorsement. The production system presented here is the final version from the project team.

The production system contains six elements: credible contactor, partnership, technology, people, industrialisation and company culture. Each of these elements consists of a set of principles, the numbers of which vary from element to element. In this setting, two elements are particularly important: people and the company way. The principles governing these two elements strongly indicate the wish for participation, initative/improvement and competence liability. 25

The production system as such is intended to stimulate increased efforts for improvement, with the aim of maintaining or increasing competitiveness. One way to stimulate improvement and innovation is to invite employees to participate actively. This may be done in a variety of ways, but one approach is to encourage employees to come up with suggestions for improvement. A relevant tool for collecting such proposals is the proposal box. The case company has operated a manual proposal box system for many years. This manual system failed to deliver, due to slow handling of suggestions and the high cost associated with the case handling. When a proposal was physically delivered in the proposal box, the co-ordinator who administered the system had to register it and decide who should evaluate the proposal. Then the proposal was handed over to the assessor; depending on

25 The company focuses on participation and training to develop competence liability, which is the ability of each individual to work independently, participate and take responsibility for his/her own workplace. The company's employees are able to take responsibility for more than their own job and thus ensure the suitability of the working environment, HSE, productivity and innovation. 
the size and character of the proposal it might require more than one assessor for evaluation. In addition, the department manager had to comment on the proposal.

As part of the Simplex project, it was decided that a digitalisation of the proposal box system was needed to enable continued employee participation.26 A digitalised system was provided to enable much faster processing of proposals. The system was also expected to allow communication with the proposer(s) during the processing of a proposal, so that they would know at any given time at which step of the proposal handling system their proposal was located. At the same time, the system opened up the use of tools familiar from social media, such as thumbs up, likes, comments and evaluation. Not only did this provide indications of the quality of the proposal, it also made it possible for colleagues to comment on each other's proposals and thus contribute to rapid handling of suggestions. Consequently, by developing and implementing a digital proposal box, a number of improvements have been introduced:

- Suggestions may be delivered from an employee's cell phone (all employees have their own cell phone sponsored by the company).

- Co-workers can comment on, like or evaluate suggestions.

- Proposers are able to follow the whereabouts of their proposal in the process.

- Communication between the proposal box system administrator (department head) and the proposor(s) is dramatically improved.

- Proposals may be promoted using pictures and videos from cell phones.

- Documentation beyond pictures and videos may be uploaded.

- All types of proposals and improvement projects are handled in the same system.

- Management is provided with an overview of numbers and estimated savings.

Most important is the structural facilitation of participation in the design of the handling system. The handling and prioritising of proposals will for the most part be undertaken by democratic committees, which consist of union representatives, safety delegates (democratically elected from among the employees) and both blue- and whitecollar workers, in addition to management. This ensures insight, involvement and influence on both strategic and practical decisions.

A fundamental challenge posed by the use of the digital suggestion box system is that the system allows for a farreaching flexibility with regard to the promotion of proposals. The transparent system encourages users to participate in a progressive development of proposals and in new solutions where the innovation element may be significant. This is reinforced by the fact that large groups within the organisation, through the ongoing extensive digitalisation of the company, are being introduced to large volumes of digital data that were previously unavailable to them. For the system to succeed, the ability to handle proposals quickly is essential. Thus, on the one hand, the new digital suggestion box system encourages an increased number of substantial suggestions that have to be handled thoroughly and quickly. On the other hand, it is expected that the digital system will contribute to efficiency, rather than becoming a cost driver in the handling of suggestions. The handling of this dilemma will thus become fundamental.

The case company's development initiative for facing Industry 4.0 has been presented above. On the one hand, there is a focus on developing and implementing an overall digital production system that includes the entire production process, including subcontractors and partners, and which represents an innovative force for seeking new solutions for operations in existing markets and the new markets the company is considering entering. On the other hand, a digital effort to accelerate the pace of improvement work through the digital proposal box, as well as a number of other solutions, ensures digital access to job documents, ordering of materials etc. Together, these technological developments change the prerequisites for socio-technical interaction. The changes allow for an

26 A prototype of the system is now in testing for implementation. 
organisation that is completely different from the traditional hierarchy in which the foreman or department head leads his or her crew from above by controlling the distribution of work and access to the necessary expertise.

\section{IOR vs DD for participation}

A modern company depends on constant improvements to stay competitive. Many improvements will be driven by conditions outside the company. The sources of improvement are diverse and include technological developments/new technologies, new interfaces between customer and supplier, and new construction methods that are more efficient/less resource-intensive. Even though these sources come from outside, the company has to implement internal solutions and make them more efficient (Silverstone and Hirsch 1992). Fundamentally, this is about domesticating new organisational concepts. The case company has a number of bodies, ways of operating and tools to ensure that employees participate in making sense of new concepts and technologies (Feldman 2000, Feldman and Pentland 2003), domesticating them (Silverstone and Hirsch 1992) and routinising them (Nelson and Winter 1992). When solutions and processes are optimised, efficiency is bound to improve. Nevertheless, the personnel must experience the work as meaningful and challenging.

As indicated in the case, major technological changes are taking place in the company, and this poses great challenges to the work organisation. However, technology is not deterministic; it allows for choices. Thus, the way the company decides to implement and use the technology will be of great importance to the work organisation. However, this not solely a technology issue. The way the technology is adopted may be guided by the set-up of the work organisation. The work organisation and technology must consequently be considered in context, and employees should be included and listened to in the assessment of different set-ups. Although new solutions are being implemented, there remains significant potential for progressive improvement through facilitation of the production process, better organisation etc. Gaining this potential is largely a matter of facilitating active participation by the employees. This means that strategic challenges that place major constraints on the organisation and daily improvements must both be addressed at the same time.

The core issue is which framework best promotes and supports these improvements. Above, I have presented two different STSD approaches that provide different conditions for this type of activity. The Dutch IOR approach provides a comprehensive theoretical model that focuses on removal of operational disturbances and efficient handling of repetitive disturbances within a company. This is made possible through a detailed description of levels, design parameters and evaluation of those parameters in terms of key performance indicators. This comprehensive and detailed model will somewhat limit the company's room for manoeuvre. Using IOR determines the direction in which a company will adjust its improvement field, strategically and practically. As with all STSD approaches, IOR focuses on the work organisation, the work content and the responsible competent employee (Ravn 2017); however, given the limited room for manoeuvre, this will somewhat limit the development agenda.

The other approach presented above is the Scandinavian DD. As a point of departure, this approach provides less structure by focusing on democratic dialogue and a procedural approach as the most important tools for improvement. Furthermore, the focus goes beyond the individual company. Instead of unfolding within a single organisation with networking organisational boundaries as an addition, the projects will have network building as their prime target. This focus has emerged from the modest results in programmes initiated in Scandinavia, especially in Norway (Gustavsen 2008). The spread of STS was slow, and making local/regional networks a point of departure for STS/AR was regarded as a strategic move in the right direction. Later, the concept of development coalition, which embraces several local networks, was launched (Gustavsen 2008). Such an approach involves fewer restrictions on which improvement objects/activities/projects to focus on, and may enable a stronger focus on the decisive issues for STSD, i.e., work organisation. However, the almost complete lack of focus on the relationship 
between technology and organisation in DD has led the tradition towards a pure AR approach that has trumped the focus on socio-technical systems.

Carl Pava developed an interesting multiple-step approach to the STSD of non-routine office work systems (Pava 1983, Austrom and Ordowich 2018). Based in the US, Pava was outside the IOR and DD traditions, and the foundations of his approach are of particular interest: instead of the self-managed work groups with interchangeable skills that characterise classic STSD, he focused on what he called "discretionary coalitions" and "deliberations".27 In non-routine knowledge work, deliberations form collectively built frameworks that provide clarity for the communicators without sacrificing complexity. Deliberations are carried out to illuminate problematic issues, innovation tasks etc. and may take place in different forums or settings. By focusing on discretionary coalitions using deliberation as a tool in non-routine knowledge work, Pava moved away from input-output configurations in routine work, focusing instead on the advancement and application of knowledge as the output of deliberations. This represents a whole new approach to nurturing holistic job design from most of the STSD literature. Simultaneously, Pava reinforced the importance of the design process: the process is as important as the design outcome. The outcome must be self-designing, because only the participants in the "system" can determine its nature, purpose and boundaries before designing the details. On this basis, Pava strongly emphasised the importance of participation and of maintaining a distance from the omniscient expert.

The case company is a project-based organisation. Even though much work consists of routine operations, projects differ in their complexity, distribution of work, suppliers and partners, the number of personnel required etc. This means that the organisation and personnel must be able to use deliberation and advanced knowledge sharing to solve challenging issues in any project. Pava's analyses of non-routine office work led him to introduce, or give new content to, the concepts of discretionary coalitions and deliberations. His reconfigurations capture how nonroutine work may be organised and applied to work organisation in the digital future. I therefore believe that Pava's STSD approach is a viable alternative to the two approaches outlined above. It includes the necessary structure, meets the needs for involvement, participation and ownership, and is less expert-driven.

In this paper, the case was presented to introduce a kind of combination of IOR and DD. The case company wished to develop a production system (XPS) to frame its development agenda within an overall structure that would enable the establishment of a development agenda anchored within that structure, setting the direction for the development work. XPS can thus clarify what the company regards as the most important areas for development and the reasoning behind those choices. However, this will be brought about in a less structural manner than is found in IOR. Addressing the relationship between technology and work organisation, with an open agenda concerning how technology should be put to use, will encourage engagement and help create jobs that people enjoy. However, these approaches do not fully capture the new challenges raised by Industry 4.0. The distinctions among tasks traditionally given to specific groups may be erased, technology may be widely distributed and used by "everyone" and, because of constant shifts in the type of products being produced, the same person may hold different roles in different projects or for different product types. This situation is brought about by market diversification, where the company enters new markets. As the suggestion box case indicates, new technology and its application may challenge the existing organisation, putting the traditional hierarchy under pressure.

Through the proposal box system, the company ultimately envisages increased efficiency and productivity, but with the possibility to determine the direction of those changes. The philosophy behind the proposal box system is to encourage and allow wide employee participation. Their commitments are not limited to reducing disturbances,

\footnotetext{
27 Pava introduced his own glossary in his book Managing New Office Technology: An Organizational Strategy (1983:176-180). There, he defined discretionary coalitions as "alliances of interdependent parties formed to make intelligent trade-offs that enable attainment of overall objectives; different coalitions are associated with different deliberations". He defined deliberation as "sequences of reflective and communicative acts employed to resolve problematic issues".
} 
although this may be interpreted widely. Setting structural limits on the development agenda through model restrictions (as in IOR) will consequently place unrequested limitations on the proposal box system. Limitations contrast Pava's approach which encourages new combinations and new non-traditional solutions. The proposal box system will cover both strategical important initiatives and a large number of minor developments that will encourage systemic belonging in any case. Nevertheless, Pava's approach of escaping from the input-output strait jacket may open up solutions that have not yet been considered.

\section{Conclusion}

The digital revolution sets entirely new technical preconditions for socio-technical interaction. If STSD is to remain relevant, suitable approaches must be developed within this tradition. As indicated above, established approaches such as IOR and DD will have shortcomings in terms of coping with the new digital era. Pava's non-routine office work approach, in which he introduces alternatives to classical hierarchies, seems to provide a solid point of departure.

\section{References}

Ashby W.R. (1958). An Introduction to Cybernetics, 3rd Ed. London, Chapman \& Hall.

Austrom D., \& Ordowich C. (2018). "Calvin Pava. Sociotechnical System Design for the 'Digital Coal Mines." In D. Szabla, W. Pasmore, M. Barnes, \& A. Gipson (Eds.), The Palgrave Handbook of Organizational Change Thinkers (pp. 1-31). Cham, Palgrave Macmillan.

Brynjolfsson E., \& McAfee A. (2014). The Second Machine Age: Work, Progress, and Prosperity in a Time of Brilliant Technologies. New York, Norton.

De Sitter U., den Hertog J.F., \& Dankbaar B. (1997). "From complex organizations with simple jobs to simple organizations with complex jobs." Human Relations 50.51997 Pp 497-534.

Elden M. (1983). "Democratization and participative research in developing local theory." Journal of Occupational Behaviour 4(1) Pp 21-34.

Emery F. (1959) Some characteristics of socio-technical systems. London: Tavistock Institute document no. 527

Gustavsen B. (2008). "Action research, practical challenges and the formation of theory." Action Research 6.4 2008 Pp 421-437.

Haga T. (2007). "Orchestration of networking processes.” Doctoral thesis. NTNU, Trondheim.

Eijnatten F. M. van (1993). The Paradigm that Changed the Work Place. Assen, Van Gorcum.

Emery F. (1993). "Characteristics of socio-technical systems.” In E. Trist \& H. Murray (Eds.), The Social Engagement of Social Science: A Tavistock Anthology. Volume II, The Socio-Technical Perspective (pp. 157186). London, Tavistock Institute. 


\section{E UROPEAN JOURNAL OF W ORKPLACE INNOVATION}

Feldman M.S. (2000). "Organizational routines as a source of continuous change.” Organization Science 11.6 2000 Pp 611-629.

Feldman M.S., \& Pentland B.T. (2003). "Reconceptualizing organizational routines as a source of flexibility and change.” Administrative Science Quarterly 48.1 2003 Pp 94-118.

Galbraith J.R. (1974). “Organization design: an information processing view.” Interfaces 4.31974 Pp 28-36.

Greenwood D.J., \& Levin M. (2007). Introduction to Action Research, 2nd Ed. Sage.

Nelson R.R., \& Winter S.G. (1982). An Evolutionary Theory of Economic Change. Cambridge, MA: Belknap Press of Harvard University Press.

Netland T. (2013). "Company-specific production systems: managing production improvement in global firms." Doctoral thesis. NTNU, Trondheim.

Pateman C. (1970). Participation and Democratic Theory. Cambridge University Press.

Pava C. (1983). Managing New Office Technology: An Organizational Strategy. New York: Free Press.

Pava C. (1986). "Redesigning sociotechnical systems design: concepts and methods for the 1990s." Journal of Applied Science 22.3 1986 Pp 201-221.

Ravn J. (2017). “Ansvarskompetanse.” SINTEF report 2017:00336. Trondheim, SINTEF.

Silverstone R., \& Hirsch E. (1992). Consuming Technologies: Media and Information in Domestic Spaces. London/New York: Routledge.

Vriens D., \& Achterbergh J. (2011). "Cybernetically sound organizational structures I: de Sitter's design theory." Kybernetes 40.1 Pp 405-424.

\section{About the author:}

Trond Haga, PhD, is Senior Manager at Kvaerner, Norway. Research interests include network cooperation, organization, training, collaborative industrial relations, action research, trust and sociotechnical systems theory. He has published in other journals and anthologies. 